$: \equiv \quad$ Get Access Share Export

Structural Change and Economic Dynamics

Available online 29 June 2019

In Press, Accepted Manuscript (?)

\title{
Credit risk migration rates modelling as open systems II: A Simulation Model and IFRS9-baseline principles
}

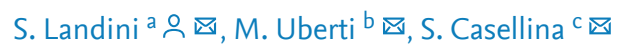

田 Show more

https://doi.org/10.1016/j.strueco.2019.06.013

Get rights and content

\section{Highlights}

- Credit risk migration rates matrices with entries, migrations of stayers and exits are simulated;

- A mathematical procedure to extrapolate future dynamics conditional to a macroeconomic

- scenario is developed;

- IFRS9 segmentation into buckets and prospective estimates of Expected Loss are introduced.

\begin{abstract}
In 2014 the International Accounting Standards Board (IASB) promulgated the current International Financial Reporting Standards 9 - Financial Instruments (IFRS9) that draw new lines for an ex-ante, reliable, unified and wellbalanced credit risk assessment. Among others, two principles are of interest to this paper: that of segmented and prospective estimation of expected credit losses. Within the frame of a micro-simulation approach, this paper focuses on these issues while considering the evolution of a bank portfolio. The paper presents an algorithmic procedure developed on a realistic dynamic credit risk migration rates modelling of a portfolio as an open system with entries and exits that is consistent with the segmented and prospective IFRS9 principles. Although operating at the aggregate level of the migration matrix, combining accounting principles inspired to those of the IFRS9-baseline with the open systems modelling, the main conclusion is that it allows for a more reliable provision and ex-ante and forward-looking estimation of expected losses.
\end{abstract}




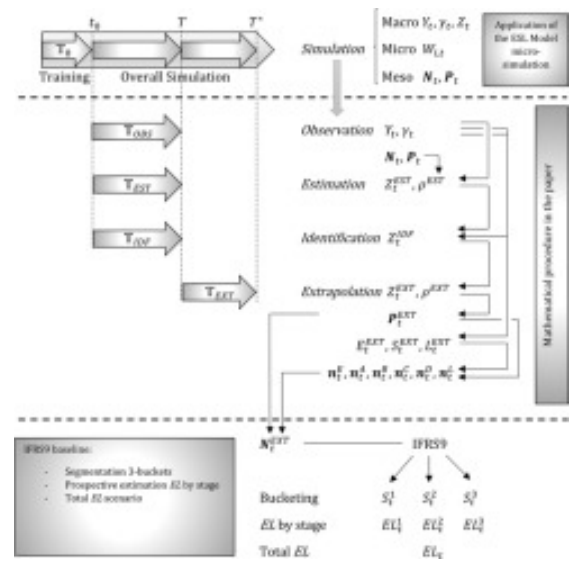

Download high-res image (139KB)
Download full-size image

\section{JEL classification}

\section{C15; C18; C53; C63; G11; G13; G17; G18; G21; G24; G28; G31; G34; G38; E47}

\section{Keywords}

Credit risk; Migration rates models; Micro-simulation; Expected loss; Accounting standards

Recommended articles Citing articles (0)

View full text

(C) 2019 Elsevier B.V. All rights reserved.

ELSEVIER About ScienceDirect Remote access Shopping cart Advertise Contact and support Terms and conditions Privacy policy

We use cookies to help provide and enhance our service and tailor content and ads. By continuing you agree to the use of cookies.

Copyright (C) 2019 Elsevier B.V. or its licensors or contributors. ScienceDirect $®$ is a registered trademark of Elsevier B.V. 